\title{
Defining Contemporary Metal Music: Performance, Sounds, and Practices
}

\section{Mark Mynett}

\begin{abstract}
Contemporary Metal Music (CMM) features, usually down tuned, harmonically distorted timbres, and from a performance perspective regularly contains fast and frequently complex subdivisions, as well as highly synchronized instrumentation. The combination of these elements results in a significant concentration of dense musical sound usually referred to as "heaviness". From a performance, sounds, practices and production aesthetics perspective, this article proposes the broad musical parameters for CMM's heaviness, and from this viewpoint likewise seeks to distinguish CMM from traditional heavy metal music.
\end{abstract}

The analytical perspective implemented in this article adopts aspects of the theoretical frameworks developed by Allan F. Moore (2001) in Rock: The Primary Text. Moore expresses the challenges encountered in imparting a definition of rock, stating, "we are always in the process of defining rock, and no formulation I shall offer can be considered definitive" (Moore 2001, p.4). There are numerous similar problems when attempting to classify musical parameters for Contemporary Metal Music (CMM) (Walser, 1993; Shuker, 2005; Weinstein, 2011). For example, there is the possibility that oversimplifications are made through excessively broad generalisations. However, Moore's sentiments regarding a model of style for rock music could be seen as equally valid when applied to CMM. Therefore, although there can be no unchanging and definitive description of CMM, the author similarly proposes that there are ways of expressing common musical sounds, performance perspectives and a coherent set of practices that are frequently shared.

In addition to proposing these common sounds, perspectives and practices, the methodology implemented in this article is further influenced by Allan F. Moore (2001). Moore distinguishes heavy metal from hard rock from the perspectives of: structure; tempo; guitar articulation; instrumentation and associated texture; vocals; and from numerous elements collectively referred to as 'formal predictability' (Moore, 2001, pp.157-151). In a comparable manner, this body of work seeks to distinguish, and provide a clear delineation between, CMM and traditional heavy metal (THM), and as "points on a style continuum" (Moore, 2001, p.148).

\section{Tempo}

The tempi of early THM songs tended to be "slow, even ponderous" but with a wider range used towards the end of the 70s (Weinstein, 1991, p.24). Allan F. Moore highlights that THM tempi tended to fall into one of two distinct speeds: 120 , or 160, beats per minute (bpm), labelled as 'up tempo' or 'frenetic' respectively, with the potential of a fifteen percent variation in each instance (Moore, 2001, p.148).

In comparison, there has been a marked overall increase for CMM performance tempi, with high tempi often being fundamental to CMM's identity. Kahn-Harris notes that modern metal tempi often fall between 150-250bpm (Kahn-Harris, 2007, p.32), and in radical recent examples, tempi sometimes exceed 350bpm for quarter note values (Berry and Gianni, 2004, p.85). Furthermore, CMM performance tempi are more likely to display dramatic changes within the song than in THM (Purcell, 2003, pp.11-24), which have a tendency to be more 
stable. However, it is important to note that it is not perhaps tempo that matters here; so much as the way that tempo influences the perception of speed.

One of the results of these higher tempi is smaller inter-onset intervals than in the comparatively slower spacious arrangements of THM, and consequently more rhythmically concentrated drum, bass, and guitar patterns. Inter-onset intervals are "the elapsed time, measured in milliseconds, between the onset of one sound and the onset of the next" (Zagorski-Thomas, 2007, p.334). These smaller metric groupings are likely to restrict the possibilities for dynamic variation, improvisation and variation of performance. Furthermore, numerous studies have been carried out that support the hypothesis that expressive timing does not scale accordingly with tempo (Collier and Collier, 1996; Friberg and Sundstrom, 2002; Honing and Has De Baas, 2008) with these authors concluding that an increase in tempo frequently results in a decrease in the amount of swing ratio found in drum performance patterns. These findings would seem to have relevance to CMM's high tempi drum patterns that are frequently performed with minimal, or no, swing, groove, or expressive timing discrepancies (sometimes referred to as 'human-feel'). These 'straight', rather than swung, drum performance characteristics partly dictate the style's aesthetic of performance precision (Haid, 2006, p.100), which in many instances can be viewed as a central rhythmic quality native to CMM.

\section{Rhythm, Subdivisions, and Ensemble Rhythmic Complexity}

Although Walser proposes that "Rhythm has been particularly neglected in Western theories of musical meaning" (Walser, 1993, p.48), it is interesting to note that he provides cursory discussion, less than two pages, to the rhythmic qualities of THM in Running with the Devil: Power, Gender and Madness in Heavy Metal Music (1993). The reasons for this could be, as Walser himself suggests, that the rhythmic elements of THM are often perceived as "very simple" (Walser, 1993, p.49). The resolute rudimentary drive often comprises of eighth and sixteenth notes, mostly with a 4 / 4 time signature, frequently in concise two or three note groupings. The author proposes that if Walser were writing this text approximately two decades later, with a focus on CMM rather than THM, then far greater analysis and consideration of rhythmic concepts would be required.

In contrast to THM's more basic pulsing structures (Walser, 1993, p.49) the rhythmic phrasing of CMM has more of a tendency to impart fluid presentation of $32^{\text {nd }}$ notes at high tempi, frequently sustained over considerable periods of time, or with complex and fragmented bursts of notes (Hutcherson \& Haenfler, 2010, p.113) regularly performed with staccato components. At its most fundamental level then, the identity of CMM denotes a tendency to focus on the intensity and intricacy of rhythmically concentrated drum, bass, and guitar patterns. THM, in contrast, has more dispersed inter-onset intervals and therefore more openness to the rhythmic patterns of the drums, bass and guitar, and is combined with more spacious instrumental arrangement.

The method in which CMM achieves this intensity of rhythm, is frequently through fast subdivisions and sub-divisional complexity of the drum, bass and guitar performances. Subdivisions represent a process of dividing a rhythmic pattern, or pulse, into lesser components than those being counted, for example a 4 / 4 measure divided into $32^{\text {nd }}$ notes. For the purposes of this article, sub-divisional complexity refers to rhythmic patterns that consist of a number of interconnecting clusters of different subdivisions, rather than consecutive repetition of continuous pulse straight subdivisions. For radical examples of fast subdivisions, and sub-divisional complexity, Swedish band Meshuggah demonstrate these conventions throughout most of their work, for example, the albums 'Chaosphere' (1998), 'Catch Thirtythree' (2005), 'ObZen' (2008) and the single song EP, divided into thirteen tracks, 'l’ (2004). 
For this style, when performances are based around fast, or complex subdivisions, high levels of synchronisation between the drums, guitar and bass are likely. For the purposes of this article, synchronisation is an adjective describing drumbeats and subdivisions, particularly relating to the bass drums, that are largely, or entirely, coordinated with the rhythmic patterns of the guitar and bass (Pieslak, 2008, p.13; Turner, 2009, p.6). Combined with higher tempi and increased sub-divisional complexity, one of the results of this synchronisation is a significant concentration of musical sounds within the space that the music resides, usually resulting in sonic properties that are considered dense. Due to the number of different instruments, or elements of instruments, synchronising and emphasising these subdivisions, this will usually result in rhythm structures that are dominant, forceful and clearly defined. These sonic conventions provide textures that are usually perceived as intense and distinctly aggressive (Pillsbury, 2006, p.5), particularly when performed at high tempi.

However, it is important to note that certain instrumentation in CMM, most often the drums, will frequently perform different sub-divisional patterns across sections where the other instruments sub-divisional patterns remain the same. This is often perceived as providing different levels of energy throughout the song structures, and a common technique here is a break down, or beat down, which Pillsbury refers to as:

Sections that either cut sixteenth note intensities into eighth-note intensities; or maintain a sense of continuous rhythm in the guitars but do so accompanied by a halftime drum pattern.

(Pillsbury, 2006, p.11)

So far this article has highlighted CMM's inclination towards the use of: high tempi; dramatic tempo changes; fast subdivisions; staccato components; increased sub-divisional complexity and high levels of synchronisation. Further to these properties, CMM has a propensity towards syncopation, which is the provisional displacement of the usual metrical accent, typically resulting in a normally-weak accent becoming accented. Collectively, these sonic structures and conventions tend to exhibit an overarching complexity in the construction of the music, and give a technical nature to these performances. However, it is relevant to note that, although CMM performances have a tendency to display complex/technical qualities, there are other forms of popular music that can often present just as, if not more, complex and technical primary performance techniques than those in CMM - examples of which would be jazz and progressive rock. In a similar manner to some of the values held by those within these music styles and scenes, the technicality of musical composition and performance complexity, sophistication and proficiency in CMM is often afforded high value and esteem by artists and enthusiasts alike (Purcell, 2003, pp.12-14), with Phillipov claiming that:

Technical complexity is often claimed as a virtue in and of itself, with fans and musicians often claiming a level of prestige for the music based on its technical difficulty. (Phillipov, 2012, p.64)

The frequently high level of synchronisation in CMM directly influences the style's ethos of performance precision and technical exactitude. This is commonly central to the identity and aesthetics of the music's performance and can be viewed as a significant stylistic marker of CMM. Precision of performance refers to the timing of drum and cymbal hits, as well as guitar and bass notes, being played very close to the intended beats, and precise fractions of beats, of the intended rhythmic sequence. To maximise the potential for accurate ensemble synchronisation, straight, metronomic performances, with minimal, or no, expressive timing variations in the performance, are frequently required. As CMM performances are predominantly based around fast and/or complex subdivisions, with high levels of accentuation or synchronisation, the concept of rhythmical perfection is a characteristic that many musicians and producers endeavor to capture and present. This results in a tight, but rarely improvisatory methodology to CMM performance. 
For many of the reasons discussed in this article so far, and particularly the higher synchronous relationship between the bass drum and rhythm and bass guitar's subdivisions and patterns, the transition from THM to CMM can be considered a repositioning that is focused on, and more concerned with, ensemble rhythmic complexity. This can be viewed as a move away from platforms of "heroic individualism" (Millard, 2004, p.169), which for THM is often characterised by individualised solo virtuosity (Waksman, 2001, p.131). With reference to THM and CMM being "points on a style continuum" (Moore, 2001, p.148), in many instances, this conversion from individual melodic virtuosity to ensemble rhythmic complexity can be viewed as a paradigm shift in the sonic conventions and performance properties distinguishing the aesthetics of these styles. Additionally, the focus on rhythm, rather than vocals or melody (Friesen and Epstein, 1994, p.4), contributes to the fundamental lack of any explicitly melodic components in a lot of CMM. Due to this focus on rhythm and ensemble rhythmic complexity, the music's main rhythmical components, often the bass drums and guitars are usually foregrounded in the mix, and therefore emphasised by the production approach.

Common rhythmic perspectives of CMM drums, bass and guitar performance will now be presented. Before doing so however, it is important to note that although CMM has a tendency to feature greatly increased sub-divisional complexity, this is not a pre-requisite for music to be considered CMM. As Pieslak highlights:

Fan identification within metal appears to be shaped at its most rudimentary and 'popular' level around the music, but in two differing aspects - sound/timbre or performance/note complexity.

(Pieslak, 2008, p.46)

The author agrees with Pieslak in this respect. Therefore, following sections broadly focused on CMM performance, a section discussing sound/timbre will be presented.

\section{Drums}

Haid highlights that metal drumming requires "stamina, athleticism, speed and agility" to achieve its core traits of "precision and speed" (Haid, 2006, p.96) Similarly, Berry and Gianni note that an "exceptional amount of endurance" is required to develop the considerable coordination, and dexterity to play the "exceptionally fast, technically challenging rhythms...most notably double bass drum patterns inherent to this style" (Berry and Gianni, 2004, p.85). Many of the CMM performance traits already highlighted result in physically concentrated drum patterns that require a higher level of technical proficiency, precision and exactitude from the performer.

\section{Blast Beats}

A CMM drum performance technique, mostly used in more extreme styles, that very much represents this more physical style of drumming is the blast beat. The blast beat is a drumming technique whereby exceptionally fast, straight and metronomic, snare hits are performed. Similar to many drumbeats, this is most usually carried out with one hand executing the snare hits, however these snare hits are "exceedingly fast to the point of losing completely their traditional backbeat function" (Pillsbury, 2006, p.202). Kahn-Harris suggests that these are performed above 300bpm (Kahn-Harris, 2006, p.32), with Phillipov proposing that blast beats are generally performed as $8^{\text {th }}$ notes (Phillipov, 2012, p.86). Phillipov goes on to outline a number of different styles of blast beat: "Simultaneous eighth notes on the ride cymbal and kick drum, plus alternate eighth notes on the snare" or varying this approach with "a one- 
handed roll technique that uses the snare's rim to create what sounds like a two-handed drum roll"; with the snare, bass drum and hi-hat or ride, being hit in unison; or "playing a sixteenth note double-kick roll while hitting eighth notes on the snare" (Phillipov, 2012, p.86).

\section{Double Bass Drums}

Double bass drums have always been of importance to heavy metal music styles, with Berry and Gianni noting that, "double bass playing is a strong characteristic of heavy metal" (Berry and Gianni, 2004, p.86). The term 'double bass drums' refers to a single bass drum, or two separate bass drums, performed in each instance with two separate beaters controlled by each of the drummer's feet. For a single bass drum, a double pedal is required, which enables two separate pedals operating two separate beaters to be connected to a single bass drum. Rondinelli and Lauren state:

Double pedals give you a more even articulation, attack and sound. Two bass drums give you a wider, broader sound. Using two bass drums of the same size, but tuned differently, or two different-size bass drums, can give you a variety of pitches to work with.

(Rondinelli and Lauren, 2000, p.5)

These sentiments highlight the sonic characteristics of a single bass drum performed with a double pedal, compared to two bass drums performed with two separate pedals. However, from a music production perspective, the perception of these differences can be highly impacted by the use of bass drum sample augmentation, or replacement, and the specific techniques and approaches employed to achieve this.

For CMM music, the previously discussed increase of tempi and sub-divisional complexity will usually result in fast, and complex, double bass drum performances. The term 'fast double bass drums' refers to high-speed bass drum subdivisions, requiring a high level of dexterity and coordination usually with a requirement of minimal, or no, dynamic variation. These highspeed bass drum subdivisions are often continued over considerable time periods, thereby requiring elevated levels of coordination, stamina, dexterity, control and strength (Berry and Gianni, 2004, p.86). The term complex double bass drums refers to double bass drum performances demonstrating complicated rhythm structures and timing complexities that consist of a number of interconnecting clusters of different subdivisions, rather than consecutive repetition of continuous pulse straight subdivisions. Referring to both fast and complex bass drum performances, and their importance to CMM, Rooney states:

These often feature $32^{\text {nd }}$ notes at extreme tempi, and complex and fragmented bass drum figures in $16^{\text {th }}$ and $32^{\text {nd }}$ note denominations. In no other form of music is the bass drum linked so closely and definitively with rhythmically complex subdivisions, indeed this relationship often underpins entire albums by certain bands.

(Rooney, 2012, personal communication).

As part of the complex and fragmented bass drum figures referred to by Rooney, accomplished double bass drummers can play anything from "polyrhythms to syncopated rhythms to rudimental style drumming with their feet (e.g. double stroke rolls, flamed rudiments etc.)" (Berry and Gianni, 2004, p.86). Berry and Gianni's reference to drum polyrhythms here has significance to CMM, as these are often utilised to provide syncopation. Sometimes referred to as cross-rhythms, the term polyrhythm refers to the simultaneous performance of two or more contrasting rhythmic pulses, normally played on differing drums, or differing elements within the drum set, which in CMM will usually involve double bass, drum patterns. Krebs proposes these multiple rhythms to be "interpretative layers whose cardinalities are different and are not multiples/factors of each other" (Krebs, 1999, p.31). 
Due to high tempi, the sub-divisional complexity of the drum and bass drum performances, and the frequently symbiotic relationship between the bass drum and rhythm and bass guitar patterns, CMM double bass drums are likely to play a vital role. For these reasons, the bass drums are "seemingly of higher importance to establishing a groove than the snares and cymbals" (Turner, 2012, p.36). Furthermore, due to bass drums suggesting intensity (Pieslak, 2008 , p. 13), it can be proposed that the smaller inter-onset intervals of CMM bass drums, resulting from fast sub-divisions, will usually result in the music being sonically intense.

The important role of the bass drums in CMM is often reflected in the music's production values, whereby this element is frequently foregrounded in the mix. Supporting this notion, Turner makes an association between the production approaches of contemporary dance music and contemporary metal, stating the requirement of the bass drum's prominence in the mix for both music styles (Turner, 2012, pp.38-39).

\section{Phrasing}

The discussion has highlighted CMM drum performances inclination toward fast subdivisions, high levels of sub-divisional complexity and the tendency for the drum patterns to synchronise with the bass and rhythm guitar's rhythmic patterns. However, there are numerous other sonic conventions that distinguish drum performances in CMM, notably in the phrasing and cymbal work. These performance techniques emphasise a focus on sound/timbre, rather performance/note complexity (Pieslak, 2008, p.46).

The author carried out a number of field interviews into various aspects of CMM drumming with Steve Rooney, who is a columnist for Drummer magazine, and artist/columnist for Rhythm magazine. As a live and recording session musician performing in the UK, European, Scandinavian and LA metal scene for over twenty-five years, Rooney has also conducted classes and seminars on metal drumming at London's Drumtech institute. Rooney highlighted linear phrasing, Afro-Cuban clave style phrasing, advanced phrasing between the shells and cymbals, and previously unused cymbal phrasings as performance techniques often used in CMM drum styles (Rooney, 2012, personal communication). Rooney's observations and explanations concerning the relevance of linear phrasing merit presenting in full:

Linear phrases by definition are drum phrases composed of sound sources 'one after another', as opposed to several sound sources played simultaneously. For example, a straight 4/4-rock beat could be typically composed of 8th notes played on hi hats or similar, snare and bass drum, played in a three-way combination simultaneously. A linear take on this would be performed mainly one sound source after another, i.e. kick, hats, snare, kick, hats, snare, no two limbs playing strokes simultaneously. These phrases are in no way particular to any subdivision and are not strict in terms of the linear principal, often being used in conjunction with traditional three or four way coordinated patterns.

(Rooney, 2012, personal communication)

Rooney emphasises Gene Hoglan's groundbreaking example of linear phrasing on the album 'Symbolic' by the band Death. Although he highlights this album as representing the first time he had heard linear phrasing used in a metal context, with expressive phrasing between the hi-hats, tom-toms, splash cymbals, and bells of cymbals, Rooney remarks that in terms of CMM performance, the concept of linear phrasing is now so commonplace as to be almost unremarkable (Rooney, 2012, personal communication).

An example of phrasing that has influenced the grooves used in CMM is Afro-Cuban clave style phrasing. Rooney argues that, due to the widespread influence of Afro-Cuban rhythms on many areas of popular music, it is natural that these would find their way into heavy music styles. 
The principle of Afro-Cuban rhythms with regard to their application on the drum set, is the repeated use of 'clave' or 'key', a simple rhythmic motif which features constantly in the pattern, for example the rhumba clave and the son clave.

(Rooney, 2012, personal communication)

Here, Rooney highlights the most obvious example of Afro-Cuban clave style phrasing influencing metal as Sepultura's (1996) album 'Roots'. The impact of Sepultura, and this album, on a global level are focused on in Kahn-Harris (2000) 'Roots'?: The Relationship Between the Global and the Local within the Extreme Metal Scene. Rooney notes that the album's title track is informed by a 3/2-rhumba clave, and rhythms considered being AfroCuban or Brazilian, influence the album as a whole. Similarly, Kahn-Harris notes that Igor Cavalera's drumming "relies on the toms as much as bass, snare and hi-hat" (Kahn-Harris, 2000, p.131). The album's widespread commercial success (Kahn-Harris, 2000, p.131) had a considerable impact on the drum beats and phrases used in metal from the late 1990's onwards, with Afro-Cuban and Latin informed rhythms regularly being adopted by artists such as III Nino and Pantera (Rooney, 2012, personal communication). Furthermore, Berry and Gianni propose, "The most advanced heavy metal grooves can also incorporate ideas from Fusion and Linear Funk" (Berry and Gianni, 2004, p.85). Fusion drum styles incorporate rock, progressive rock, jazz and funk, "and involves advanced musicianship", while linear funk "tends to be quite busy, usually featuring $16^{\text {th }}$ notes throughout an entire measure" (Berry and Gianni, 2004, p.77).

Previously unused cymbal phrasings, and advanced phrasing between the shells and cymbals, are performance techniques frequently used in CMM. Rooney discusses the way that CMM drummers have expanded both their cymbal set-ups and their use, noting that cymbals and cymbal effects that were previously the favourites of jazz, fusion and progressive drummers are now essential elements for many CMM drummers. These cymbal and cymbal effects include: oversize ride cymbal bell sounds (e.g. mega-bells, ice bells and Zildjian zil bells); dry, rasping, industrial china cymbal sounds and variations on these; smaller, trashy china cymbals rather than the larger more traditional versions; and perhaps most importantly, small and exotic splashes and mini-chinas (Rooney, 2012, personal communication).

These sound sources affected metal drummers phrasing by becoming increasingly utilised within the bar as left field percussive sounds, rather than the more straightforward end or beginning of the bar purely to punctuate. I must stress, this is not particular to metal, as jazz, fusion, progressive and funk players had been phrasing in these places for years. Rather, what changed for the metal drummers was the bleeding of these percussive techniques into 'heavy' phrasing such as double bass drums and dense tom-tom patterns. A modern metal drummer playing two sixteenth notes on a tiny splash cymbal in the middle of a tom-tom fill is now common and the 'surprise' element of these sounds cannot be overstated, however back in the mid 90's it was extremely fresh.

(Rooney, 2012, personal communication)

Drummers such as the aforementioned Gene Hoglan and Igor Cavalera, as well as Nicholas Barker (e.g. Dimmu Borgir's 2001 album 'Puritanical Euphoric Misanthropia') and Joey Jordison throughout Slipknot's four studio albums have popularised this more lavish style of cymbal phrasing to varying degrees. Additionally, more abundant use of cymbal hits and faster hi-hat, ride and cymbal subdivisions contribute to high levels of drum performance energy.

\section{Rhythm Guitar}


Pieslak proposes that fan identification in CMM appears to be shaped by performance/note complexity or sound/timbre (Pieslak, 2008, p.46). These separate emphases are similarly often reflected in the performance focus of different CMM artists. However, it is important to note these categories are not mutually exclusive, as CMM artists will frequently move on a line between the points of performance/note complexity and sound/timbre, often within the same song. The manner in which CMM's rhythm guitar performances relate to the qualities of performance/note complexity and sound/timbre will now be discussed.

CMM rhythm guitar performances typically have fast and complex subdivisions. The rhythmically concentrated patterns result in small inter-onset intervals that provide a high level of transients due to the fast picking motion of the performances. Kahn-Harris emphasises the fast subdivisions frequently found in the rhythm guitar performances of CMM by noting that some riffs (short repeated rhythm phrases) are played at 500-600 notes per minute (KahnHarris, 2007, p.33). Fast subdivisions such as these frequently involve the guitarist exploiting "the rhythmic potential of repeated pitches" (Pillsbury, 2006, p.129). Recurring rhythmic phrases, or motifs, repeated at the same pitch is sometimes referred to as ostinato. Playing the same single pitch, rather than different pitches, enables faster subdivisions, which in CMM are regularly played in the guitar's lower registers. These repeated low notes are a generic identifier of metal (Pillsbury, 2006, p.197) that produce a "stable affective base" (Pillsbury, 2006, p.11). Furthermore, playing these fast subdivisions with the same single pitch, rather than a chord, provides a clearer and more prominent identification of a low root tone. Pieslak proposes, "In this lower register...the fifth of the power chord tends to obscure rather than reinforce the fundamental or root in more active passages" (Pieslak, 2007, p.220).

In CMM, the repetition of single pitch rhythmic patterns in the guitar's lower registers, often centres on the use of the guitar's lowest open string, which refers to the lowest pitch on the guitar's register. Low pitch can be seen as vital to the overall sonic impact of CMM, due to its deep and dark timbre. Additionally, the lowest open string provides an enhanced level of mobility for the guitarist's fretting hand, and therefore features highly in CMM's riffs, and key selection.

Furthermore, CMM riffs frequently use the lowest open string as the pitch from which other notes, or chords, alternate, often in the form of pedal points. A pedal point is a note, typically in the bass range, around which different notes, or a note, are played in another register. In CMM, these low pedal notes are often played with small staccato, complex and fragmented metric groupings, and performed with palm muting.

Alternatively, single pitches are repeated in very quick succession at a fixed pulse, and played smoothly without any breaks between the notes, referred to as legato. This technique is often referred to as tremolo picking. When performed without, or with minimal, application of palm muting but with an inclination towards using the guitar's mid, rather than lower, range of notes, tremolo picking is a heavily used rhythm guitar technique of the black metal subgenre.

CMM's highly concentrated rhythm guitar patterns with minimal, or no, swing, groove, or expressive timing discrepancies, that are highly synchronised with the drums and bass, marks a paradigm shift toward a form of rhythmic guitar virtuosity that makes the same sound more than once very fast. This is a change from Walser's ideas of individualised guitar virtuosity in THM, which, while also based on fast notes, is focused on different notes, performed melodically.

Walser states that guitar solos are "virtually required by the conventions of the genre" (Walser, 1993, p.54) which "features at least one guitar solo" in almost every song (Walser, 1993, p.50). However, CMM regularly presents songs without guitar solos. This is due to the tendency for the backing element(s) of CMM guitar solo sections to be focused on intensity of rhythm, rather than harmonically liberating note, or chord, sequences. 
Although CMM rhythm guitar performance has an inclination toward single pitch rhythmic patterns, it also has a tendency towards the use of diads and triads, rather than full chords of four to six notes. This is due to diads and triads, two and three note chords respectively, retaining more clarity and definition than full chords, when performed with the high levels of distortion that is characteristic of this rhythm guitar style. In addition to using root and fifth, or root and fourth intervals known as power chords, these diads and triads are frequently major or minor third, diminished fifth, or minor sixth intervals. When played as part of a pedal point riff, these diads and triads are often played without being palm muted.

In combination with high tempi and fast, often staccato, ostinato, and complex, subdivisions, palm muting frequently signifies CMM's rhythmic treatment of guitar performances. Palm muting is a playing technique whereby the outer side of the palm of a guitarist's picking hand is placed across the area where the strings go onto the bridge of the guitar. This creates a more percussive, staccato, effect than otherwise, by shortening the sustain time. This emphasises the transient envelope of the note, or chord, consequently enhancing the performance's rhythmic characteristics. Due to the sonic modification benefits that palm muting provides to a guitar's rhythmic characteristics, it has become an essential playing technique in CM. Pillsbury proposes:

By greatly emphasising both the lower frequencies and the very high over-tones of the sound envelope, as well as cutting out the mid-range, palm muting results in a distortion timbre that generally sounds tighter and more precise. Furthermore, palm muting produces a distinctively percussive timbral variation.

(Pillsbury, 2006, p.11)

Furthermore, Phillipov points to palm muting contributing to a "distinctly percussive distortion timbre" (Phillipov, 2012, p.82), which Pillsbury suggests is a generic identifier and rhetorical device (Pillsbury, 2006, p.xxv). CMM guitar riffs will frequently accentuate the rhythmic characteristics of a guitar riff by alternating between heavily palm muted single pitch rhythmic patterns in the guitar's lower registers, and non-palm-muted notes, or chords, played elsewhere on the fretboard.

CMM frequently displays a tendency towards atonality and dissonance (the lack of fixed scale intervals or note harmony respectively) frequently through the use of chromatic progressions (Phillipov, 2012, p.xv), and the use of the flattened second interval, often resulting in the perception that the music lacks a key signature.

These qualities tend to point towards "The pivotal influence of black musics (particularly the blues) on the development of metal has progressively been erased" (Kahn-Harris, 2007, p.137). Blues, and blues-rock, aesthetics frequently provided a great deal of inspiration for THM. However, it can be noted that in CMM, the use of blues based intervals as utilised by, for example, Jimi Hendrix, and blues elements in general, are usually avoided, particularly with vocals. This results in less pentatonicism in the riffs, and less use of double-stopped (two notes played simultaneously) thirds and fourths played in the mid and upper registers of the guitar. This consequently tends to result in higher degrees of segregation between the sections of rhythm and lead guitar in CMM.

In addition to the diminished impact of blues music, folk influences are less often encountered in CMM. In contrast, classical, and particularly baroque influences regularly continue to be appropriated, assimilated and adapted. Here, classical "refers to the musical tradition of Mozart and Beethoven, of Tchaikovsky, Stravinsky and Stockhausen" (Moore, 2001, p.9). The baroque music era from 1600-1750 is often considered as representing a move away from the harshness of medieval and early renaissance music, and tends to be characterised by the rich 
counterpoint and distinct melodic lines of Johann Sebastian Bach, George Frideric Handel and Antonio Vivaldi.

\section{Sound/Timbre}

In CMM, the pursuit of heavier guitar and bass timbres is normally facilitated by the now widespread use of scordatura, which refers, in this instance, to the open strings of the guitar, and bass, being provided with an alternative tuning. This normally takes the form of down tuning, which is a term used to describe a musical instrument being deliberately tuned with a lowered system of pitches. Pitch can be seen as vital to the overall sonic impact of metal and down tuning provides a deeper, heavier and darker timbre. This alters the playing experience of the instrument, due to the resulting difference in the tension of the strings, and will usually necessitate the re-intonation of the guitar. Additionally, tuning down a standard gauge string can result in poor sound, because the string will be at a much lower tension than intended, and therefore heavier string gauges are required when down tuning (Kahn-Harris, 2007, p.32). However, performing with down tuned guitars can present numerous challenges, which the player's performance technique will need to compensate for. Despite the use of heavier strings, the radically different string tension will normally result in a wider oscillation of the string, particularly on the thicker strings where most of the rhythm guitar parts will be played. This makes it notably harder to retain tuning and intonation during performance, particularly when considering the aggressive picking nature of the style.

Although there are exceptions, for example the black metal subgenre (Kahn-Harris, 2007, p.32), regular pitch tuning (with thickest $/ 6^{\text {th }}$ string [guitar] - thickest $4^{\text {th }}$ string [bass] tuned to 'E') is more associated with THM. In contrast, down tuning is often considered to be a prerequisite for the overall sonic impact of CMM. The thickest string features heavily in the rhythm guitar and bass performances, and the most common of these down tunings involve this string being tuned to a ' $\mathrm{C}$ ' or ' $\mathrm{B}$ '. This is four or five semi tones, respectively, lower than this string would normally be pitched for regular pitch tuning. The rest of the strings are then lowered by the same degree, thereby retaining the usual intervals between the strings, or lowered by a tone less than the interval that the thickest string was lowered. The latter alternative provides a root/fifth/octave power chord on the three thickest strings when played unfretted or on the same fret, which on the guitar can relatively easily be achieved with a single finger. This presents a new, highly mobile, context for power chords that tend to feature heavily in the rhythm guitar performances for CMM.

As already stated, down tuning in this manner provides a deeper, darker and heavier sound, with a greater movement of air from loudspeakers reproducing the amplified sound, due to the lower fundamental frequency. When guitars and bass are down tuned to $\mathrm{C}$, the fundamental frequency for the guitar is $65.407 \mathrm{~Hz}$ and $32.703 \mathrm{~Hz}$ for bass (Katz, 2002). When guitars and bass are down tuned to $\mathrm{B}$, the fundamental frequency for the guitar is $61.735 \mathrm{~Hz}$ and $30.868 \mathrm{~Hz}$ for bass (Katz, 2002). These extended low frequencies provide numerous challenges when capturing, and presenting these timbres.

Further to the impact of down tuning, there has additionally been a marked increase in the heaviness of timbres involved with CMM. Berger and Fales state "Heaviness is the defining feature of the genre" (Berger and Fales, 1997, p.181) and Berger proposes, "The history of metal is commonly understood as the pursuit of greater and greater heaviness" (Berger, $1999 b$, p.59). Although the subjective term 'heaviness' can refer to "a wide range of instrumental timbres and compositional elements" (Berger and Fales, 1997, p187), it is most frequently used to describe the sonic weight and density of the low and low-mid frequencies. It is also used to describe the sonic power of electric guitars when projected via tonal modification and appropriate amplification (Walser, 1993, p.2; Berger, 1999b, p.58; Weinstein, 1991, p.23). One essential ingredient of this is the deliberate introduction of distortion. Moylan proposes that "Distortion sounds and other processing effects may also provide additional 
spectral information and added density to the primary pitch area" (Moylan 2007, p.226). This emphasises the connection between distortion and rhythm guitar heaviness/density. Berger and Fales argue that the characteristic guitar timbres of each new wave have had a tendency towards becoming heavier and heavier over time (Berger and Fales, 1997, p.182) and for metal guitarists, the history of guitar technology has seen a progression towards ever-heavier tones (Berger, 1999b, p.58). This progression is often by way of developments in high-gain, valve guitar amplification technology, providing and with these higher-gain capabilities an accompanying reduction of dynamics. Valve amplifiers are the most common form of amps used for metal music, as "Tubes tend to have a more musical, even order harmonic aspect to their clipping distortion" (Huber and Runstein, 1997, p 313). With characteristics better suited to down tuning, these new breed of amplifiers have provided the ability for musicians and producers to achieve significantly heavier and denser rhythm guitar timbres whilst still retaining the vital quality of note definition. Providing a concise description of note definition is challenging, due to this largely relating to timbre, which "presents specific difficulties that soon challenge the capabilities of the written word" (Hugill, 2008, p.175). However, in relation to overdriven rhythm guitar sounds, note definition can be considered as the clarity and definition of pitch, in the form of notes and chords, and the intelligibility, and ability, to detect this pitch when the guitar sound is placed in the context of a mix. Note definition reflects strong qualities in the guitar's sound envelope characteristics, an appropriateness of spectral content, particularly in the low frequencies around the fundamental, the minimal bearing of unmusical resonant frequencies, and the appropriateness of influence that distortion has on spectral content and dynamic range.

\section{Bass}

Due to the focus on ensemble rhythmic complexity in CMM, the bass often simply 'doubles' the guitar riffs (effectively playing the same performance part, but an octave lower). Consequently, CMM bass performance often employs the same subdivisions and performance techniques as the rhythm guitar, but normally with a greatly diminished application of palm muting. Alternatively, simpler subdivisions are often employed, resulting in notes that are sustained across the guitar's rhythmic patterns. For these reasons, some CMM bands have a tendency to look at the bass as mainly an instrument that renders the guitar riffs with a greater level of perceived heaviness.

These bass performance traits in CMM are often different from those in THM. This is frequently due to the slower tempi and more pulsing rhythms of THM, with a reduced focus on accentuation and synchronisation. These qualities tend to afford bass performances in THM with more musical space for rhythmic and melodic movement.

Due to the nature of down tuning in $\mathrm{CMM}$, the region of frequencies and sonic space conventionally provided to the bass in music production is frequently impacted to a considerable degree by the frequency content of the rhythm guitars. These significantly lower fundamental frequencies of the rhythm guitar reside in an area normally allocated to the bass. This provides a particular challenge in providing separation and definition to the bass in CMM.

\section{Vocals}

Vocal performance in THM has always required a clear and often overt presentation of emotionality, usually through tone of voice, as a display of authenticity (Weinstein, 1991, pp.26-27). In contrast to THM, CMM vocal performance could be perceived as displaying confrontational hostility with aggression often involved in the delivery. Phillpov notes the "progressive elimination of recognizable signifiers of vocal melody and clarity" as metal has evolved (Phillipov, 2012, p.76). Berry and Gianni propose "The heavy metal sound initially relied on high-pitched singers, but has since evolved to embrace lower-range roaring vocals" 
(Berry and Gianni, 2004, p.85), which avoid the use of sustain and vibrato (Kahn-Harris, 2007, p.32). Furthermore, these performances rarely feature vocal harmonies, or significant variations in the strength or timbre of the voice, and are often so guttural as to fail to present any distinguishable note or pitch (Berger, 1999a, p.164).

Walser points to THM's operatic style with "long sustained notes" as suggesting "intensity and power" (Walser, 1993, p.45). However, in CMM, this intensity and power can be provided by even higher perceptions of volume, which overdriving the vocals through shouting, or screaming, provides. This results in greater levels of vocal distortion and is likely to be associated with aggression. Phillipov highlights that CMM often rejects "the melodic foregrounding of the singing voice that is crucial to emotional identification in popular music" (Phillipov, 2012, p.126), which Hodgson suggests, also reinforces the perceptions of loudness conveyed by these productions (Hodgson, 2010, p.181).

Although this section has noted the evolving vocal styles from THM to CMM, less melodic vocal characteristics are not a pre-requisite for music to be considered CMM. Furthermore; it is frequently the case that bands that employ guttural, non-pitch based vocal styles will also use clean vocal melodies. This will often be within the same song, and sometimes within the same line.

\section{Performance, Sounds, and Practices Defining Contemporary Metal Music - Summary}

There are numerous difficulties when attempting to classify musical parameters for this style of music (Walser, 1993; Shuker, 2005; Weinstein, 2011). However, to summarise, the performance perspectives, sounds, and practices that are commonly shared within CMM are:

- High tempi and dramatic tempo changes

- Fast subdivisions and sub-divisional complexity of the drums, bass and rhythm guitars, often with a requirement of minimal dynamic variation

- Small inter onset intervals, resulting in rhythmically concentrated drum, bass, and guitar patterns

- A focus on synchronisation between the drums, guitar and bass resulting in a significant concentration of musical sounds within the space that the music resides

- An overarching aesthetic of performance precision, frequently resulting in metronomic style performances, reflecting minimal, or no, swing, groove, or expressive timing discrepancies.

- Linear, linear funk, fusion and Afro-Cuban clave style drum phrasing, as well as advanced phrasing between the shells and cymbals

- An overall focus on ensemble rhythmic complexity

- The use of syncopation, staccato components, and small metric groupings

- Highly distorted, and harmonically dense rhythm guitar sounds

- The use of down tuning

- High speed down, and alternate, picking, and palm muting

- The bass and rhythm guitar's use of single note ostinato phrasing with fast subdivisions, predominantly in these instruments lower registers

- The use of diads, and triads, that are based on major or minor third, diminished fifth, or minor sixth intervals, as well as chromatic progressions, atonality and dissonance and the use of the flattened second interval

- Key selection and pedal points that favour the guitar's open sixth, or thickest, string

- The foregrounding of the music's main rhythmical components, often the bass drums and guitars

- The avoidance of blues, and blues-rock, aesthetics and the appropriation of classical and baroque influences 
- Deep, guttural, distorted vocal sounds which avoid the use of sustain and vibrato, rarely feature significant variations in strength or timbre, and often fail to present any distinguishable note or pitch

CMM artists will often explore different dynamics, styles and expressions within one song (Hoffstaft and Nagenborg, 2010, p.41) and not all CMM will demonstrate all of these features. However, it is unlikely that certain music would be considered CMM without demonstrating at least some of these features.

\section{References}

Berger, H., and Fales, C. (2005) 'Heaviness' in the Perception of Heavy Metal Guitar Timbres: The Match of Perceptual and Acoustic Features over Time'. In: Green and Porcello (eds.) Wired for Sound: Engineering and Technologies in Sonic Cultures. Middletown, CT: Wesleyan University Press.

Berger, H. (1999a). Death Metal Tonality and the Act of Listening. Popular Music, 18(2), pp.161-178.

Berger, H. (1999b) Metal, Rock and Jazz: Perception and the Phenomenology of Musical Experience. Hanover, N.H.: University Press of New England.

Berry, M., and Gianni, J. (2004) The Drummer's Bible: How to Play Every Drum Style from Afro-Cuban to Zydeko. Tucson AZ: See Sharp Press.

Clarke, E. (2005) Ways Of Listening: an ecological approach to the perception of musical meaning: New York: Oxford University Press

Collier, G., and Collier, L. (1996) The Swing Rhythm in Jazz. In Proceedings of the 4th International Conference on Music Perception and Cognition. pp. 477-480.

Friberg, A., and Sundström, A. (2002). Swing ratios and ensemble timing in jazz performance: Evidence for a common rhythmic pattern. Music Perception, 19(3), pp.333-349.

Friesen, B., and Epstein, J. (1994) 'Rock ' $n$ ' Roll Ain't Noise Pollution: Artistic Conventions and Tensions in the Major Subgenres of Heavy Metal Music' In: Popular Music and Society, 18, (3), p.1.

Gibson, J. (1979) The Ecological Approach to Visual Perception. Boston: Houghton Mifflin.

Haid, M. (1996) In: Budofsky, A. (2006). The Drummer: 100 years of Rhythmic Power and Invention. Cedar Grove, NJ: Hal Leonard Corporation.

Hodgson, J. (2010) Understanding Records, A Field Guide to Recording Practice. New York, London: The Continuum International Publishing Group Ltd.

Honing, H., and Bas de Haas, W. (2008). Swing once more: Relating timing and tempo in expert jazz drumming. Music Perception, 25(5), pp.471-476.

Howlett, M. (2009) The Record Producer as Nexus: Creative Inspiration, Technology and the Recording Industry. Unpublished PhD thesis. University of Glamorgan.

Huber, D., and Runstein, R. (2005) Modern Recording Techniques. Burlington, MA, Oxford, 
UK: Elsevier.

Hugill, A. (2008). The Digital Musician. New York: Routledge.

Hutcherson, B., and Haenfler, R. (2010). Musical Genre as a Gendered Process: Authenticity in Extreme Metal. Studies in Symbolic Interaction, 35, pp.101-121.

Kahn-Harris, K. (2000) 'Roots'?: the Relationship between the Global and the Local within the Extreme Metal scene. Popular music, 19(01), pp.13-30.

Kahn-Harris, K. (2007) Extreme Metal: Music and Culture on the Edge. Oxford and New York: Berg, p.2-5.

Katz, B. (2002) Mastering Audio: The Art and the Science. Burlington, MA: Focal Press.

Krebs, H. (1999) Metrical Dissonance in the Music of Robert Schumann. New York: Oxford University Press.

Millard, A. (2004) The Electric Guitar: a History of an American Icon. Maryland: Johns Hopkins University Press.

Moore, A. F. (2012) Song Means: Analysing and Interpreting Recorded Popular Song, Ashgate Publishing Ltd.

Moylan, W. (2007) The Art of Recording: Understanding and Crafting the Mix, 2nd ed. Boston: Focal Press.

Phillipov, M. (2012) Death Metal and Music Criticism: Analysis at the Limits. Lanham, Md: Lexington.

Pieslak, J. (2008). Sound, text and identity in Korn's 'Hey daddy'. Popular Music, 27(1), pp.3552.

Pillsbury, G. (2006) Damage Incorporated: Metallica and the Production of Musical Identity. New York and London: Routledge.

Purcell, N. (2003) Death Metal Music: the Passion and Politics of a Subculture. Jefferson, NC: McFarland and Company.

Rondinelli, B., and Lauren, M. (2000) The Encyclopedia of Double Bass Drumming. Cedar Grove, NJ: Modern Drummer Publications.

Shuker, R. (2005) Popular Music. The Key Concepts. Oxon and New York: Routledge.

Turner, D. (2009) 'Outlining The Fundamental Production Aesthetics Of Commercial Heavy Metal Music Utilising Systematic Empirical Analysis'. In: Art of Record Production Conference [online] http://www.artofrecordproduction.com/content/view/231/114/ [Accessed 24 June 2010].

Turner, D. (2012) Profiling a Metal Mastermind: The Mixing Techniques of Andy Sneap. Unpublished PhD thesis. University of Glamorgan.

Waksman, S. (2004) California Noise: Tinkering with Hardcore and Heavy Metal in Southern California. Social Studies of Science. London, Thousand Oaks CA, New Delhi: Sage Publications Ltd, (34) No. 5 pp.675-702. 
Walser, R. (1993) Running with the Devil: Power, Gender and Madness in Heavy Metal Music. Hanover, N.H.: Wesleyan University Press.

Weinstein, D. (1991) Heavy Metal: A Cultural Sociology. New York, N.Y.: Maxwell Macmillan International.

Weinstein, D. (2011) How Is Metal Studies Possible? Journal for Cultural Research, 15:3, pp.243-245.

Zagorski-Thomas, S. (2007) The Study of Groove. Ethnomusicology Forum, 16:2, pp.327335.

\section{Discography}

Dimmu Borgir (1999) Spiritual Black Dimensions. Compact Disc. Nuclear Blast. NB 349-9.

Meshuggah (1998) Chaosphere. Compact Disc. Nuclear Blast NB 2736163362.

Meshuggah (2004) I. EP. Fractured Transmitter Records CD HA001.

Meshuggah (2005) Catch 33. Compact Disc. Nuclear Blast America NB 1311-2.

Meshuggah (2008) ObZen. Compact Disc. Nuclear Blast America NB 11937. 